\title{
Sonoelectrochemical Synthesis of Silver Nanoparticles in Sodium Polyacrylate Solution
}

\author{
Orest Kuntyi ${ }^{1 \mathbb{( D}}$, Mariana Shepida ${ }^{1, *}{ }^{\mathbb{D}}$, Martyn Sozanskyi ${ }^{2}$, , Yuriy Sukhatskiy ${ }^{1(\mathbb{D})}$, \\ Artur Mazur ${ }^{1}$ (D), Andriy Kytsya ${ }^{3}$ (D), Liliya Bazylyak ${ }^{3}$ (D) \\ 1 Department of Chemistry and Technology of Inorganic Substances, Lviv Polytechnic National University, Lviv, 79013, \\ Ukraine \\ 2 Department of Physical, Analytical and General Chemistry, Lviv Polytechnic National University, Lviv, 79013, Ukraine \\ 3 Department of Physical Chemistry of Fossil Fuels of the Institute of Physical-Organic Chemistry and Coal Chemistry \\ named after L.M. Lytvynenko of the National Academy of Sciences of Ukraine, Lviv 79060, Ukraine \\ * Correspondence: maryana_shepida@ukr.net;
}

Scopus Author ID 57203884662

Received: 1.12.2020; Revised: 28.12.2020; Accepted: 30.12.2020; Published: 3.01.2021

\begin{abstract}
The paper shows the effectiveness of a "green" synthesis of silver nanoparticles (AgNPs) in sodium polyacrylate (NaPA) solutions by sonoelectrochemical method using silver sacrificial anodes. Using the cyclic voltammetry in the ultrasonic field in the range of $\mathrm{E}$ from 1.0 to $-1.0 \mathrm{~V}$, the temperature and NaPA concentration are the main parameters influencing the rate of synthesis and the size of AgNPs. As these parameters increase, the rate of nanoparticle synthesis increases. According to TEM studies, with increasing temperature and decreasing NaPA concentration, there is a tendency to increase the size of AgNPs. However, in all of the cases, the size of AgNPs does not exceed $30 \mathrm{~nm}$. Using the UV-Vis spectroscopy, it was found that the position of the absorption peak at c.a. $500 \mathrm{~nm}$, corresponding to the silver nanoparticles, is practically not shifted during numerous cycles. This fact may indicate the stability of sonoelectrochemical synthesis of AgNPs in time. Synthesized AgNPs revealed high antibacterial activity against gram-positive and gram-negative strains of typical pathogens of nosocomial infections, demonstrating the prospect of using sonoelectrochemical technique for obtaining silver colloids as a component of bactericidal drugs.
\end{abstract}

Keywords: sonoelectrochemical synthesis; silver nanoparticle; sodium polyacrylate; silver electrode, antimicrobial activity.

(C) 2020 by the authors. This article is an open-access article distributed under the terms and conditions of the Creative Commons Attribution (CC BY) license (https://creativecommons.org/licenses/by/4.0/).

\section{Introduction}

Silver nanoparticles (AgNPs) are the most investigated objects among known ones at present and have great potential in a broad range of applications [1] due to their catalytic activity, high antimicrobial efficiency, they are effective as drug-delivery carriers; at the same time, they possess by anti-thrombogenic, antiplatelet and antihypertensive properties [1-4]. Due to the problem of bacterial resistance [4], AgNPs are considered as alternative antibacterial nanobiotics.

The functional properties of AgNPs significantly depend on their geometry, i.e., shape, and size [4-6].

In the tuple "method and parameters of synthesis $\rightarrow$ geometry of nanoparticles $\rightarrow$ properties $\rightarrow$ function $\rightarrow$ field of application" the first element is crucial. Therefore, the maximum control over nanoparticles' formation at the stages of their nucleation and growth is 
one of the main criteria for choosing the synthesis method [6-9]. At present, the most common are chemical methods, which include reduction of $\mathrm{Ag}^{+}$ions to $\mathrm{Ag}^{0}$ and stabilization of the formed nanoclusters (AgNCs) and AgNPs [3, 7, 10-12]. At the same time, in the last decade, we can observe a trend towards "green" synthesis, which involves the use of non-toxic precursors, and, above all, of natural origin $[11,12]$. They mainly represent by themselves the reducing agents and surfactants simultaneously. However, regardless of the nature of precursors, the chemical reduction does not provide in the process of synthesis of a stable concentration of reducing agent, metal ions, and the ratio of their concentrations. Accordingly, the controllability of the synthesis of metal nanoparticles becomes more complicated in terms of their geometry. These parameters are decisive for the rate of nucleation and growth of nanoparticles [13-15]. Therefore, in the last decade, we can observe an increased interest in the electrochemical synthesis of AgNPs, which allows regulating the rates of these processes by the values of cathode potentials or cathode current densities [16-21]. The last parameters are controlled, and the formation of nanoparticles is controlled accordingly. Also, electrochemical synthesis is performed without a chemical reducing agent, and for electrolysis with sacrificial silver anodes [17, 19-21] without Argentum salt. This reduces the number of precursors in the solution, contributing to the control of AgNPs synthesis and meets the criteria of "green" technologies.

In the last decade, the studies of the effects of ultrasonic fields on the intensification of the electrochemical synthesis of metal nanoparticles (MNPs) increased [22-27]. In addition, sonoelectrochemical synthesis increases the design possibilities of MNPs and makes the method highly competitive with the more conventional ones. However, the references have a little description of the mutual influence of the parameters of sonoelectrochemical synthesis and the nature of the surfactant on the formation of metal nanoparticles' solutions. This hinders the creation of theoretical foundations of sonoelectrochemical synthesis of MNPs and, accordingly, hinders the development of controllable techniques of their production.

The proposed study aimed to study the "green" synthesis of AgNPs in sodium polyacrylate (NaPA) solutions by sonoelectrochemical method using silver sacrificial anodes. $\mathrm{NaPA}$ is a non-toxic anionic polymeric surfactant, which is used as an effective stabilizer of silver nanoparticles during chemical $[28,29]$ and electrochemical $[20,21]$ syntheses.

\section{Materials and Methods}

\subsection{Electrochemical measurements.}

Cyclic voltammetric studies were carried out using a standard three-electrode electrochemical cell (volume is $50 \mathrm{~mL}$ ) and potentiostat PI-50-1. Silverplate $\left(14,4 \mathrm{~cm}^{2}\right)$ were used as working and auxiliary electrodes. The reference electrodes Ag/AgCl (EVL-1M4 was purchased from "Systema Optymum" Lviv, Ukraine) mounted in a Luggin capillary containing $1 \mathrm{~mol} \mathrm{~L}^{-1} \mathrm{KNO}_{3}$ were used. The working electrode was polished using alumina slurry $(0.5 \mu \mathrm{m})$ before each scan. The scan rate of the potential was $50 \mathrm{mV} \mathrm{s}^{-1}$ in the range of $E$ from +1.0 to $-1.0 \mathrm{~V}$. The study of the anode behavior of silver was carried out in solutions of NaPA at $\mathrm{pH}$ $=8.0 \ldots 9.5, \mathrm{t}=2 \ldots 60^{\circ} \mathrm{C}$ and the concentration of $\mathrm{NaPA}$ was $1 \ldots 10 \mathrm{~g} \mathrm{~L}^{-1}$.

For sonoelectrochemical synthesis of colloidal solutions of silver nanoparticles, an ultrasonic emitter of the magnetostrictive type "Ultrasonic Disintegrator" UD-20 (Poland) was used (Figure 1). The frequency of ultrasonic radiation is $22 \mathrm{kHz}$. The useful specific power of ultrasonic radiation is $40 \ldots 62.5 \mathrm{~W} \mathrm{dm}^{-3}$ Isothermal conditions of sonoelectrochemical 
synthesis of colloidal solutions of silver nanoparticles were provided by UTU-4 ultrathermostat.

The UV-vis spectra of the colloidal solutions containing silver particles were recorded by UV/vis spectrophotometer ULab 108UV (ULab, China) using $1 \mathrm{~cm}$ cuvette at wavelength range 190-1100 $\mathrm{nm}$. The comparison solution is distilled water.

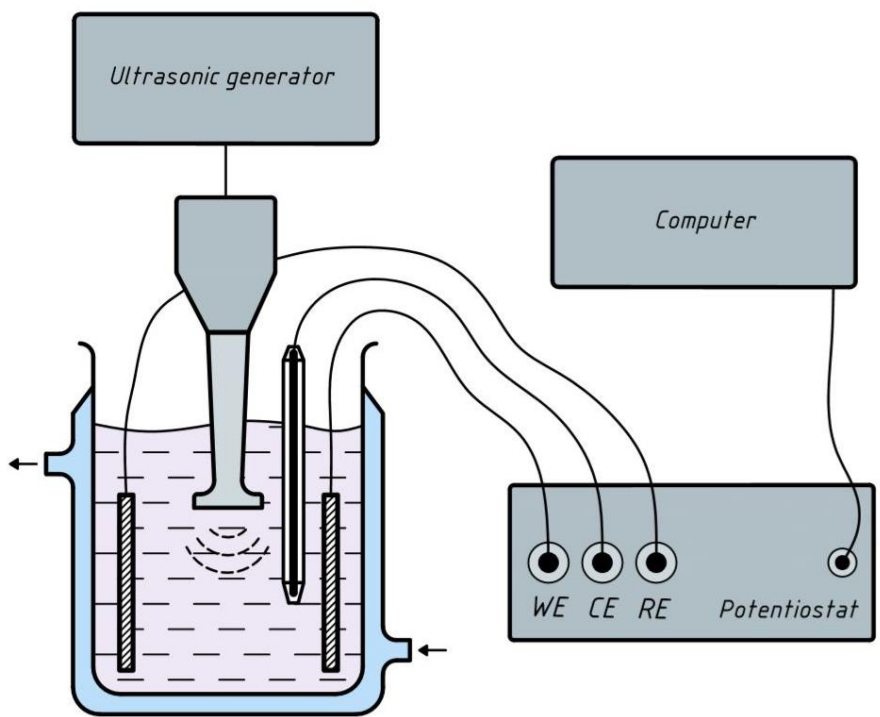

Figure 1. Sonoelectrochemistry set-up used in the production of colloid solutions silver nanoparticle.

TEM images of the samples were recorded using a JEM-I230 (JEOL, Tokyo, Japan) with an acceleration voltage of $80 \mathrm{kV}$. The samples for TEM investigations were prepared by drying $0.05 \mu \mathrm{L}$ of silver sol on the carbon grid at room temperature. The diameters of obtained AgNPs were determined using TEM images by comparing individual particles' sizes with the scales presented on images.

\subsection{Investigations of the antimicrobial activity of AgNPs.}

Staphylococcus aureus ATCC 25923 (gram-positive bacteria), Escherichia coli ATCC 25922 (gram-negative bacteria), and Candida albicans ATCC 885-653 (fungi) were used as test strains for the investigations of antimicrobial activity of synthesized AgNPs. These strains are typical pathogens of nosocomial infections. Suspensions (suspensions density equals 0.5 units on the McFarland scale) with test strains of each microorganisms species were preliminarily prepared using a Densi-La-Metr instrument. A container containing $1 \mathrm{~cm}^{3}$ of suspension with a certain test strain, $9 \mathrm{~cm}^{3}$ of colloidal solution of synthesized AgNPs was added. After 1, 6, 18, and 48 hours of exposition, the reseeding of a system consisting of a suspension with a specific test strain and a colloidal solution of AgNPs stabilized with NaPA solution on Petri dishes with a solid selective medium were performed. As a nutrient media for Staphylococcus aureus, Escherichia coli, and Candida albicans, the yellow-salt agar, Endo agar, and Saburo agar were used, respectively.

\section{Results and Discussion}

During the electrochemical synthesis of AgNPs by nonstationary current supply [20] (cyclic voltammetry), in particular, in NaPA solutions and the presence of sacrificial anodes, undergo the reactions of the formation of $\left[\left(\mathrm{Ag}^{+}\right)_{\mathrm{mPA}}\right]^{(\mathrm{n}-\mathrm{m})-}(1)$ complexes followed by their reduction and the formation of nanoclusters $\left[\left(\mathrm{Ag}^{0}\right)_{\mathrm{mPA}}\right]^{\mathrm{n}-}$ (2). The number of atoms $(\mathrm{m})$ in 
nanoclusters and, accordingly, their sizes depend on the duration of the reduction process and the concentration of $\mathrm{PA}^{-}$ions. Moreover, the growth process is multi-stage with the formation of intermediate positively charged "magic" cluster $\operatorname{Ag}_{\mathrm{x}}{ }^{+}$[28].

In the anode period: $\quad \mathrm{mAg}+\mathrm{PA}^{\mathrm{n}-} \rightarrow\left[\left(\mathrm{Ag}^{+}\right)_{\mathrm{mPA}}\right]^{(\mathrm{n}-\mathrm{m})}$

In the cathode period: $\quad\left[\left(\mathrm{Ag}^{+}\right)_{\mathrm{mPA}}\right]^{(\mathrm{n}-\mathrm{m})-}+\mathrm{me} \rightarrow\left[\left(\mathrm{Ag}^{0}\right)_{\mathrm{m}} \mathrm{PA}\right]^{\mathrm{n}-}$

In the ultrasonic field, there is an intensification of processes in the anode and cathode periods. Thus, the anode currents increase by c.a. $30 \%$ (Figure 2) and, accordingly, the rate of generation of the precursor $\left[\left(\mathrm{Ag}^{+}\right)_{\mathrm{mPA}}\right]^{(\mathrm{n}-\mathrm{m})-}$ for the synthesis of AgNPs via reaction (1) is increased. The reason for this is the depolarizing effect of ultrasound due to the acceleration of diffusion in the electrode layer.

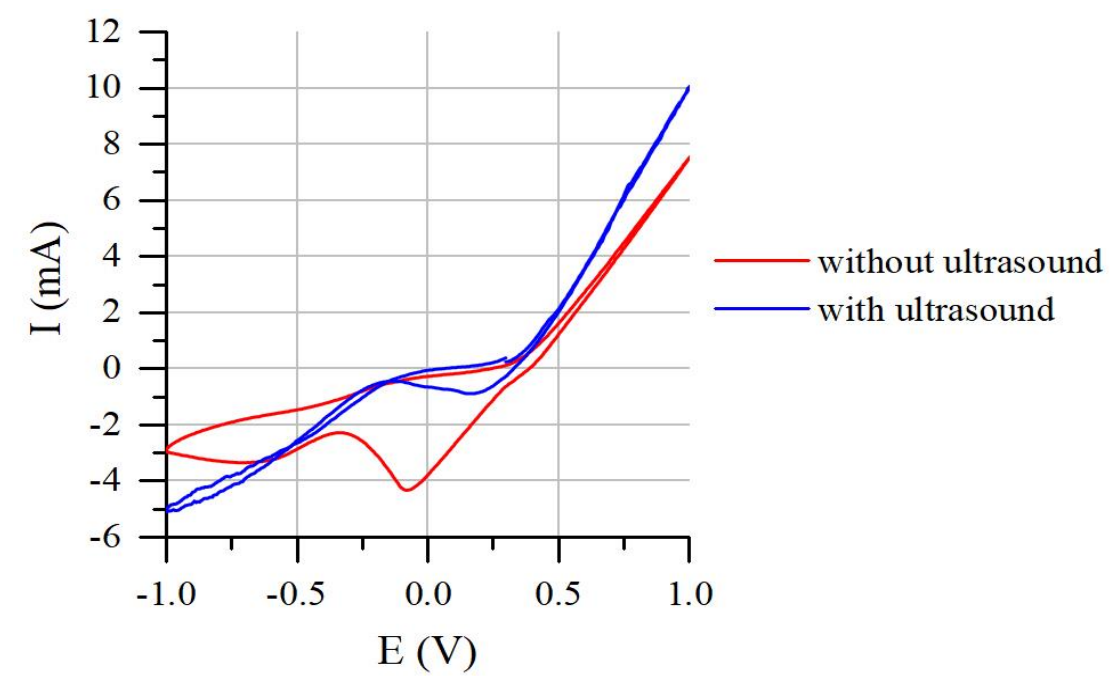

Figure 2. Cyclic voltammograms of the redox processes of silver in a water solution of $\mathrm{NaPA}\left(5 \mathrm{~g} \mathrm{~L}^{-1}\right)$ in the ultrasonic field and without it.

Ultrasound also significantly accelerates the reduction of ions $\left[\left(\mathrm{Ag}^{+}\right)_{\mathrm{mPA}}\right]^{(\mathrm{n}-\mathrm{m})-}$ with the formation of AgNPs (Figure 3). This is because simultaneously with the electrochemical reduction in the cathode period (2), there is a reduction by radicals formed during sonolysis of water [30, 31] and the decomposition of organic compounds [32]. First of all, these are the radicals $\mathrm{H}$. (3) and R (4). The latter can be formed by sonolysis of surfactant. Therefore, the sonochemical reduction of $\mathrm{Ag}(+)$ by radicals can be represented by the reaction equation $(5$, 6).

$$
\begin{aligned}
& \left.\left.\left.\mathrm{H}_{2} \mathrm{O}\right)\right)\right) \rightarrow \mathrm{H} \cdot+\cdot \mathrm{OH} \\
& \mathrm{RH}+\cdot \mathrm{OH}(\cdot \mathrm{H})))) \rightarrow \mathrm{R} \cdot+\mathrm{H}_{2} \mathrm{O}\left(\mathrm{H}_{2}\right) \\
& {\left[\left(\mathrm{Ag}^{+}\right)_{\mathrm{mPA}}\right]^{(\mathrm{n}-\mathrm{m})-}+\mathrm{mH} \cdot \rightarrow\left[\left(\mathrm{Ag}^{0}\right)_{\mathrm{mPA}} \mathrm{P}\right]^{\mathrm{n}}+\mathrm{mH}^{+}} \\
& {\left[\left(\mathrm{Ag}^{+}\right)_{\mathrm{mPA}}\right]^{(\mathrm{n}-\mathrm{m})-}+\mathrm{mR} \cdot \rightarrow\left[\left(\mathrm{Ag}^{0}\right)_{\mathrm{mPA}}\right]^{\mathrm{n}-}+\mathrm{mR}^{\prime}+\mathrm{mH}^{+}}
\end{aligned}
$$

Using the UV-vis spectroscopy, it was found that in the presence of the ultrasonic field, the AgNPs formation rate in times exceeds the AgNPs formation rate without the action of the ultrasonic field. This fact is illustrated in Figure 3 by increasing the absorption peak at $500 \mathrm{~nm}$, which corresponds to the absorption of AgNPs. This indicates the crucial role of reactions (5, 6 ) in reducing $\operatorname{Ag}(\mathrm{I})$. The reactions $(5,6)$ cause the formation of nanoclusters, in particular, the intermediate positively charged "magic" cluster $\mathrm{Ag}_{\mathrm{x}}{ }^{+}$[28], which corresponds to the maximum absorption in the ultraviolet region about $350 \mathrm{~nm}$ (Figure 3,a). Over time, the intensity of this maximum is decreased, and in 2-3 days, it is disappeared. Simultaneously, the intensity of the 
maximum at $500 \mathrm{~nm}$ increases, which is due to the process of reduction of the "magic" cluster $\mathrm{Ag}_{\mathrm{x}}{ }^{+}$and their subsequent enlargement with the formation of AgNPs nanoparticles.
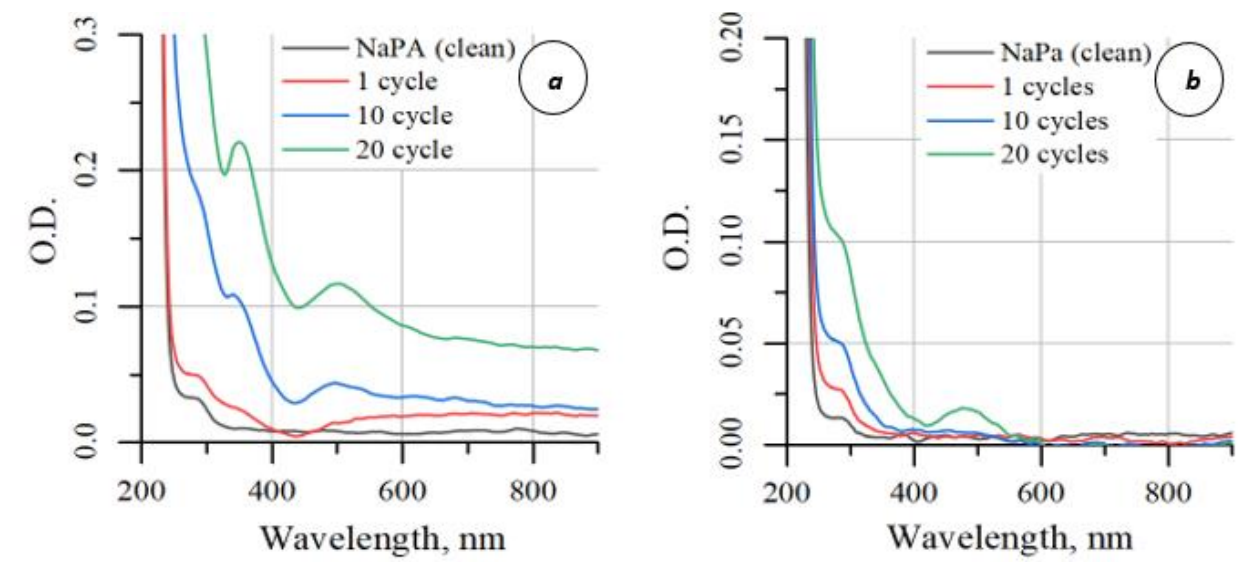

Figure 3. UV-Vis spectra of silver nanoparticles synthesized in a water solution of $\mathrm{NaPA}\left(5 \mathrm{~g} \mathrm{~L}^{-1}\right)$ in the ultrasonic field $(\boldsymbol{a})$ and without it $(\boldsymbol{b}), \mathrm{t}=20^{\circ} \mathrm{C}$.

The ultrasonic field also promotes the formation of nanoparticles smaller in size compared to AgNPs electrochemically synthesized without ultrasound (Figure 4). This is due to the acceleration of mass transfer in the bulk of the solution (overall mass transport, increasing reaction rates). Accordingly, the reduction reactions of $\mathrm{Ag}(+)$ proceed with higher rates, which contributes to the process of nucleation, i.e., the formation of nanoclusters. The latter corresponds to a clear maximum of $350 \mathrm{~nm}$ (Figure 3,a). During electrochemical synthesis without ultrasound (Figure 3,b), only the "shoulder" at $200 \mathrm{~nm}$ is observed, which can be attributed to the so-called "magic" cluster $\mathrm{Ag}_{\mathrm{x}}{ }^{+}$[28].
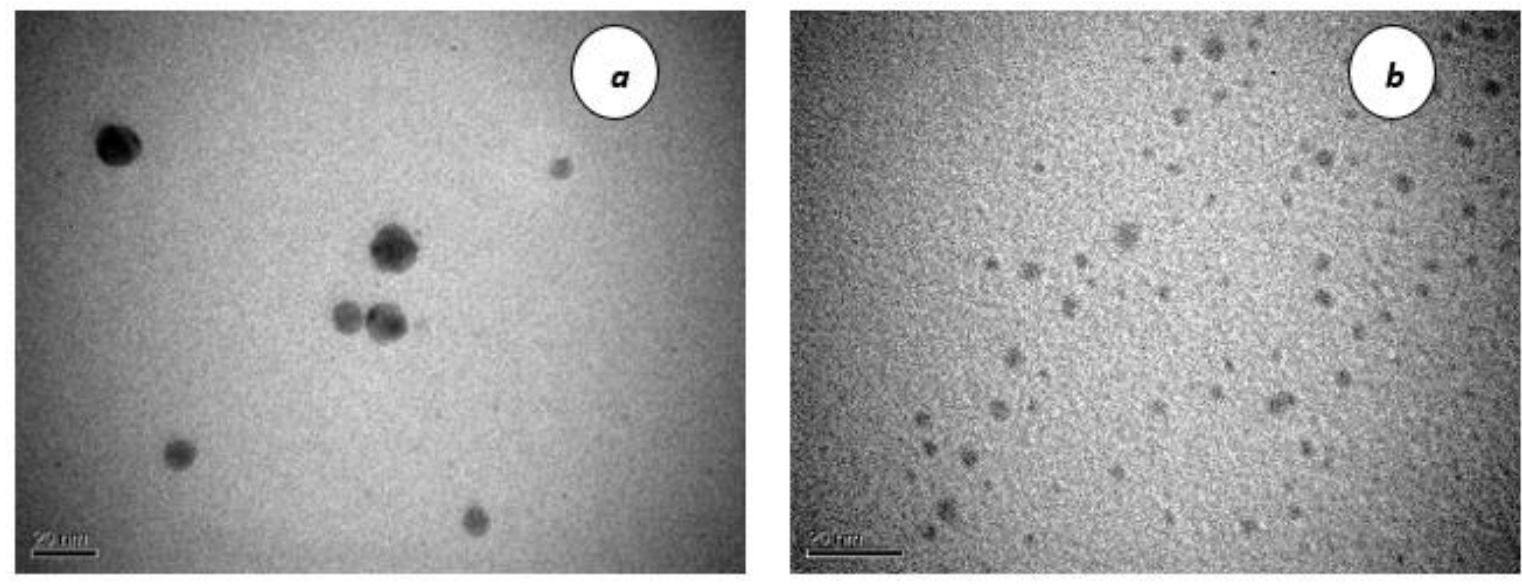

Figure 4. TEM images of AgNPs synthesized in solution NaPA $\left(5 \mathrm{~g} \mathrm{~L}^{-1}\right)$ by cyclic voltammetric (during 20 cycles) without ultrasonic field (a) and in the ultrasonic field (b), $\mathrm{t}=20^{\circ} \mathrm{C}$.

During numerous voltammetry cycles in the ultrasonic field, the values of anodic currents corresponding to silver dissolution by reaction (1) are changed slightly (Figure 5, a). The absorption maxima positions at $350 \mathrm{~nm}$ and $500 \mathrm{~nm}$, corresponding to the nanoclusters and nanoparticles of silver, respectively, are practically not shifted during numerous cycles (Figure 5, b). Therefore, sonoelectrochemical synthesis of AgNPs is stable over time. 

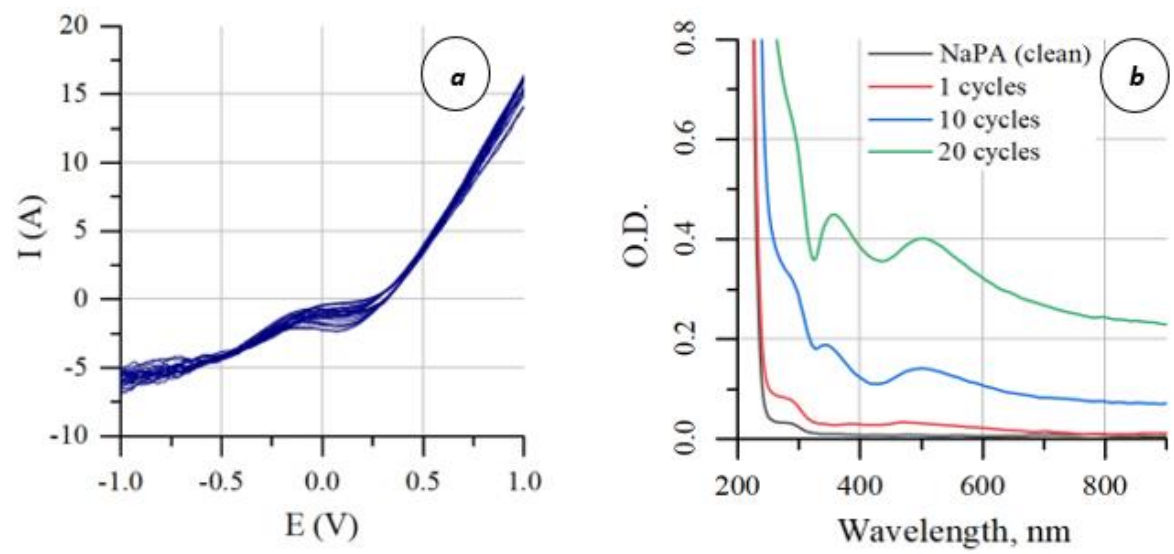

Figure 5. Cyclic voltammograms of silver in water solution NaPA $\left(5 \mathrm{gL}^{-1}\right)$ (a) and UV-Vis spectra of silver nanoparticles synthesized in the ultrasonic field $(\mathrm{b}), \mathrm{t}=20^{\circ} \mathrm{C}$.

The main factors influencing the process of synthesis of AgNPs by non-stationary electrolysis and sacrificial electrodes are the surfactant's temperature and concentration [20, 21].

\subsection{Influence of temperature.}

With an increase of temperature by $10{ }^{\circ} \mathrm{C}$, the increase of the anode currents' values does not exceed $40 \%$ (Figure $6, a$ ), which indicates the diffusion nature of the process.

The effect of temperature on the rate of formation of AgNCs and AgNPs is much more noticeable only in the range of $20 \ldots 30{ }^{\circ} \mathrm{C}$ (Figure $6, b$ ). Thus, the maxima at 350 and $500 \mathrm{~nm}$ with increasing temperature from 20 to $30{ }^{\circ} \mathrm{C}$ increases in $\sim 1.5$ and $\sim 3$ times, respectively. Some increase in AgNCs and AgNPs formation rate is also observed in the range of $30-50{ }^{\circ} \mathrm{C}$. A further increase of the temperature does not cause an increase in the maximum at $500 \mathrm{~nm}$, and the maximum at $350 \mathrm{~nm}$ is transformed into the "shoulder". Such transformation of UVvis spectra may indicate that the increase of a temperature accelerates the transformation of AgNCs into AgNPs.

One of the features of sonoelectrochemical synthesis of nanoparticles in solution is a sharp increase of temperature and pressure in the collapse of cavitation bubbles, leading to heating of the solution due to thermal conductivity. Intensification of diffusion processes as well as heat and mass transfer processes is one of the primary effects of ultrasonic (acoustic) cavitation.

At the temperature of $20^{\circ} \mathrm{C}$, the dispersing effect of cumulative high-velocity microjets (secondary effect of ultrasonic cavitation), which occur in the final stage of flattening of cavitation bubbles, causes the uniform distribution of $\mathrm{Ag}^{0}$ nuclei in the volume of solution and promotes the formation of silver nanoclusters and their subsequent slow transformation into nanoparticles. Therefore, a synergistic effect of these factors (namely, dispersing action and the presence of a stabilizer) in creating of steric barriers and, accordingly, an energy barrier, to counteract of Van der Waals forces between nanoparticles, which hindered their agglomeration ( $\sim 60 \%$ of nanoparticles with sizes in the range of $4 \ldots 6 \mathrm{~nm}$, Fig. $7 a$ ) was observed.

At higher temperatures $\left(30\right.$ and $50{ }^{\circ} \mathrm{C}$ ) the intensity of desorption of surfactant molecules (sodium polyacrylate) from the surface of nanoclusters and silver nanoparticles increases significantly. The rheological characteristics of the solution (viscosity and density) are decreased, which increases the probability of nanocluster collisions in solution. In addition, the long-term dispersing effect of ultrasonic radiation on solutions of silver nanoparticles 
contributes to the emergence of uncompensated charges on the surface of nanoparticles, i.e. an increase of surface energy.
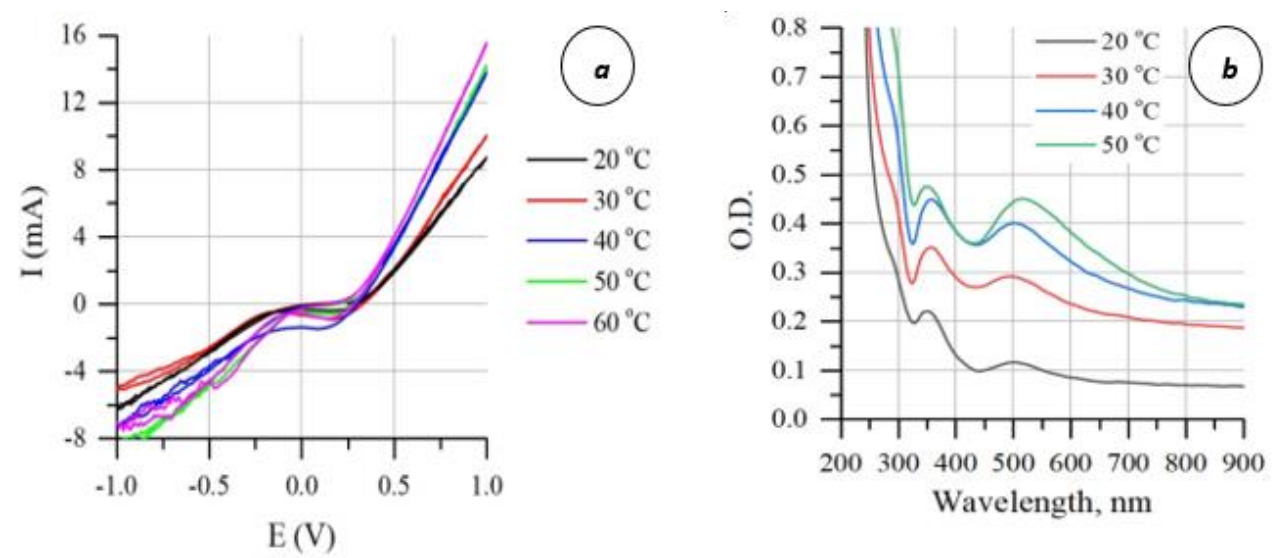

Figure 6. Cyclic voltammograms $(a)$ and UV-Vis spectra $(b)$ of silver nanoparticles synthesized in water solution NaPA $\left(5 \mathrm{gL}^{-1}\right)$ at different temperatures $\mathrm{t}=20-60{ }^{\circ} \mathrm{C}$. Scan rate of $50 \mathrm{mVs}^{-1}$.
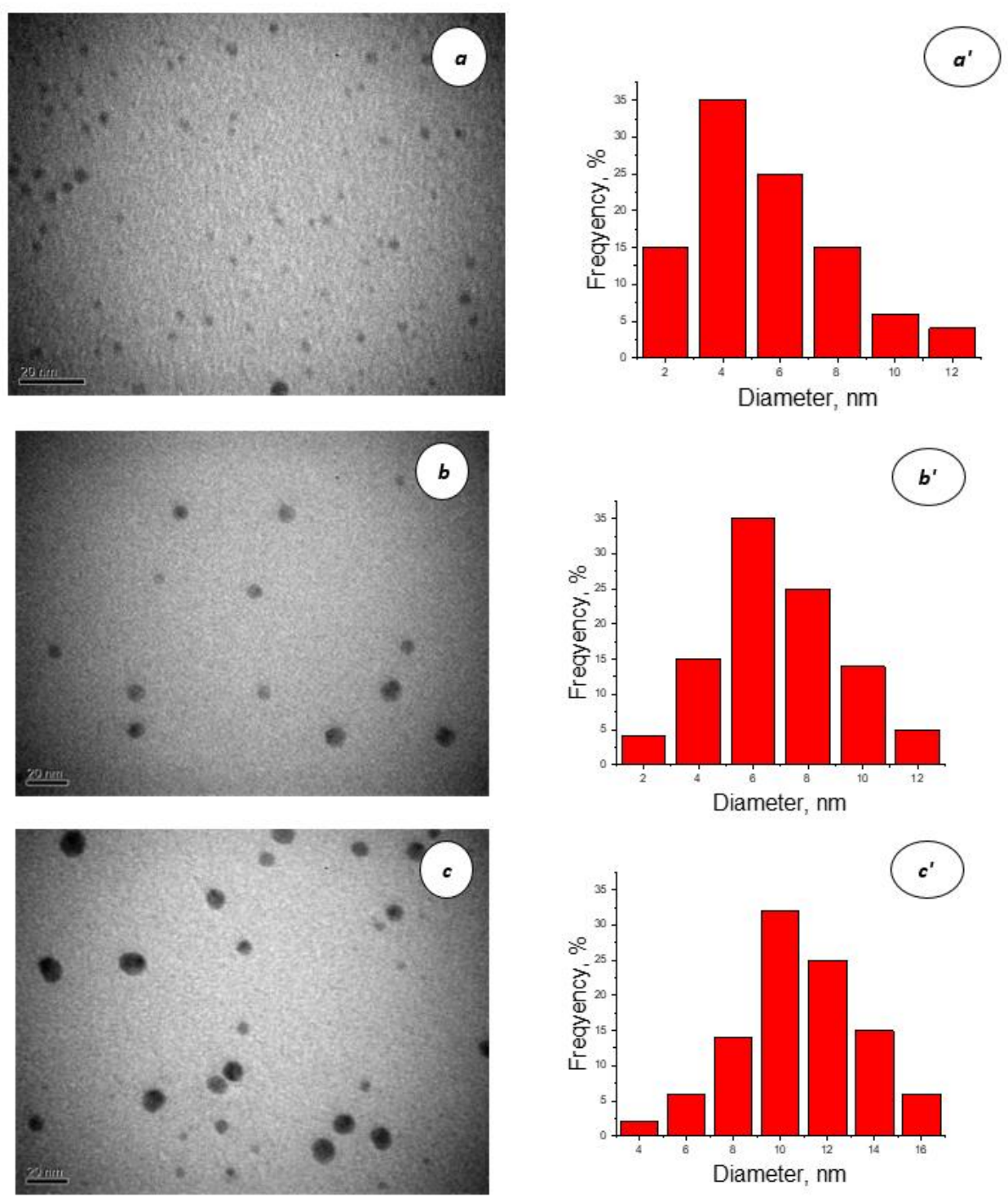

Figure 7. TEM images of AgNPs, synthesized in solution NaPA $\left(5 \mathrm{~g} \mathrm{~L}^{-1}\right)$ at different temperatures $\mathrm{t}=20(a), 30$ (b), $50(c){ }^{\circ} \mathrm{C}$ and histograms of the normal distribution of AgNPs at appropriate temperature $\left(a^{\prime}, b^{\prime}, c^{\prime}\right)$. 
The synergism of three factors (desorption of surfactant molecules from the surface of nanoclusters and silver nanoparticles; decrease in density and viscosity of the solution; the occurrence of uncompensated surface charges) caused the formation of the thermodynamically unstable system, and it was illustrated by the agglomeration of nanoclusters and silver nanoparticles, $i$. e . by increasing of the size of obtained AgNPs. That is why at higher temperatures $\left(30,50{ }^{\circ} \mathrm{C}\right)$, the removal of steric interference increases the rate of transformation of nanoclusters into nanoparticles. As a result, at a temperature of sonoelectrochemical synthesis of $30{ }^{\circ} \mathrm{C}$ the, size of about $60 \%$ of nanoparticles were in the range of $6 \ldots 8 \mathrm{~nm}$ (Fig. $7 b^{\prime}$ ), but at a temperature of $50{ }^{0} \mathrm{C}$ the, sizes of $\sim 60 \%$ of nanoparticles were larger and were in the range of $10 \ldots 12 \mathrm{~nm}$ (Fig. $7 c^{\prime}$ ).

With increasing temperature, there is a tendency to increase the size of nanoparticles (Figure 7). However, even at $50{ }^{\circ} \mathrm{C}$, the diameter of AgNPs does not exceed $20 \mathrm{~nm}$. Therefore, the temperature range of $20-50{ }^{\circ} \mathrm{C}$ is rational for the sonoelectrochemical synthesis of AgNPs.

\subsection{The effect of NaPA concentration.}

Increasing the concentration of surfactants, which are polymeric ligands, promotes the anodic reaction (1). This causes an increase of the anode currents (Figure 8) and, accordingly, the generation of complexions $\left[\left(\mathrm{Ag}^{+}\right)_{\mathrm{mPA}}\right]^{(\mathrm{n}-\mathrm{m})}$. Since such complexes are the precursors of AgNPs, increasing the concentration of NaPA is an effective factor in the increase in the rate of sonochemical synthesis of nanoparticles.

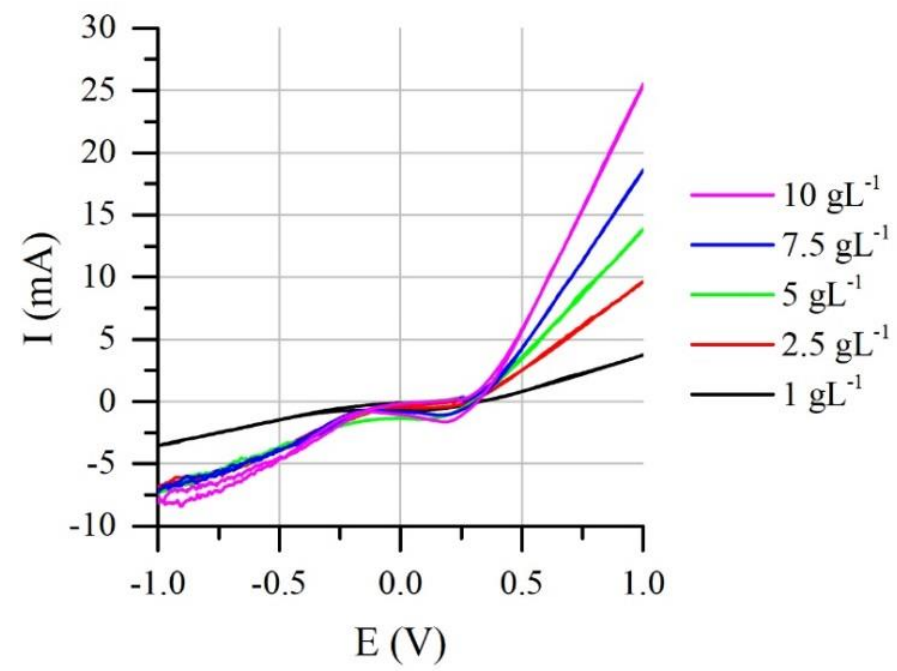

Figure 8. Cyclic voltammograms of silver at different NaPA concentrations at $50{ }^{\circ} \mathrm{C}$. Scan rate of $50 \mathrm{mVs}^{-1}$

As the concentration of polyacrylate ions increases, there is a tendency to decrease the size of AgNPs (Figure 9). This is due to the increase of the efficiency of stabilization of nanoparticles and is characteristic for chemical [28, 29] and electrochemical [20, 21] methods of metal nanoparticles preparation.

\subsection{Antibacterial activity of solutions of synthesized AgNPs.}

High antibacterial efficiency of silver nanoparticles is achieved due to their developed surface, which provides maximum contact with the environment. Such nanoparticles are also quite small and can penetrate cell membranes to affect intracellular processes from within. The bactericidal effect of silver nanoparticles strongly depends on their size and increases with decreasing size of AgNPs. The main requirements for AgNPs as for component of 
antimicrobial drugs for biomedical purposes (in particular, in the manufacturing of bactericidal solutions, bandages, etc.) are their hydrophilicity and low toxicity. From this point of view, obtained AgNPs solutions are very promising due to 1) sonoelectrochemical synthesis involves the absence of toxic precursors; 2) NaPA as a stabilizer is a hydrophilic and low toxic agent [33]. That is why the antimicrobial activity of obtained colloidal solutions of AgNPs was investigated (see Tables 1 and 2).
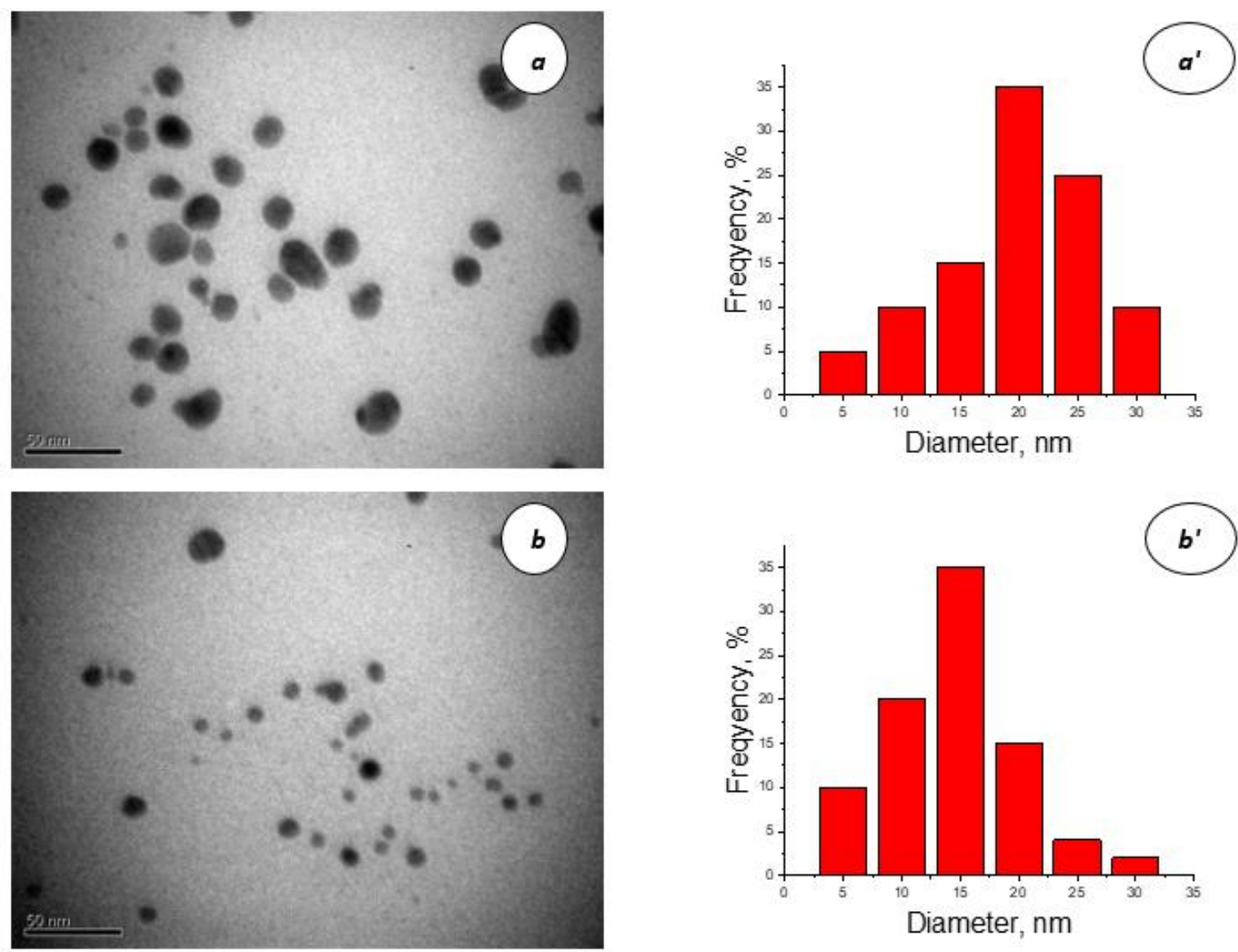

Figure 9. TEM images of AgNPs obtained in NaPA solution $\left(\mathrm{t}=50^{\circ} \mathrm{C}\right) \mathrm{C}=1 \mathrm{~g} \mathrm{l}^{-1}(\mathrm{a}) ; \mathrm{C}=5 \mathrm{~g} \mathrm{l}^{-1}$ (b) and histograms of the normal distribution of AgNPs at appropriate concentrations (a', $\left.b^{\prime}\right)$.

Table 1. Antimicrobial (disinfectant) properties of AgNPs synthesized at $20{ }^{\circ} \mathrm{C}$ and NaPA concentration equal

\begin{tabular}{l|c|c|c}
\multirow{4}{*}{ Test strain } & Exposure time, hours & $\begin{array}{c}\text { The number of } \\
\text { microorganisms, CFU/cm }\end{array}$ & Disinfecting action \\
\hline \multirow{3}{*}{$\begin{array}{l}\text { Staphylococcus aureus } \\
\text { ATCC 25923 }\end{array}$} & 1 & 150 & - \\
\cline { 2 - 4 } & 6 & not found & + \\
\cline { 2 - 4 } & 18 & not found & + \\
\cline { 2 - 4 } Escherichia coli & 48 & not found & + \\
ATCC 25922 & 1 & not found & + \\
\cline { 2 - 4 } & 6 & not found & + \\
\cline { 2 - 4 } & 18 & not found & + \\
\cline { 2 - 4 } Candida albicans & 48 & not found & + \\
\cline { 2 - 4 } & 1 & not found & + \\
\cline { 2 - 4 } & 6 & not found & + \\
\cline { 2 - 4 }
\end{tabular}

CFU - colony-forming units;

+ pronounced antimicrobial (disinfecting) effect (no growth of microorganisms);

- no antimicrobial (disinfectant) action (available growth of microorganisms). 
Table 2. Antimicrobial (disinfectant) properties of AgNPs synthesized at $50{ }^{\circ} \mathrm{C}$ and NaPA concentration equal

\begin{tabular}{l|c|c|c}
\multirow{4}{*}{ Test strain } & \multicolumn{3}{|c}{ to $5 \mathrm{~g} / \mathrm{L}}$. \\
& Exposure time, hours & $\begin{array}{c}\text { The number of } \\
\text { microorganisms, CFU/cm }\end{array}$ & Disinfecting action \\
\hline \multirow{3}{*}{$\begin{array}{l}\text { Staphylococcus aureus } \\
\text { ATCC 25923 }\end{array}$} & 1 & 180 & - \\
\cline { 2 - 4 } & 6 & 3 & - \\
\cline { 2 - 4 } & 18 & not found & + \\
\hline \multirow{3}{*}{$\begin{array}{l}\text { Escherichia coli } \\
\text { ATCC 25922 }\end{array}$} & 48 & not found & - \\
\cline { 2 - 4 } & 1 & 40 & + \\
\cline { 2 - 4 } & 6 & 9 & + \\
\cline { 2 - 4 } $\begin{array}{l}\text { Candida albicans } \\
\text { ATCC 885-653 }\end{array}$ & 18 & not found & + \\
\cline { 2 - 4 } & 48 & not found & + \\
\cline { 2 - 4 } & 1 & not found & + \\
\cline { 2 - 4 } & 6 & not found & +
\end{tabular}

The antimicrobial properties of AgNPs can be explained by two different mechanisms: 1) fixation of AgNPs on cell membranes subsequent by their penetration into the cell with subsequent damage of the membrane and release of cell contents (so-called "trojan-horse mechanism") [34]; 2) release of $\mathrm{Ag}^{+}$ions, which have antimicrobial properties.
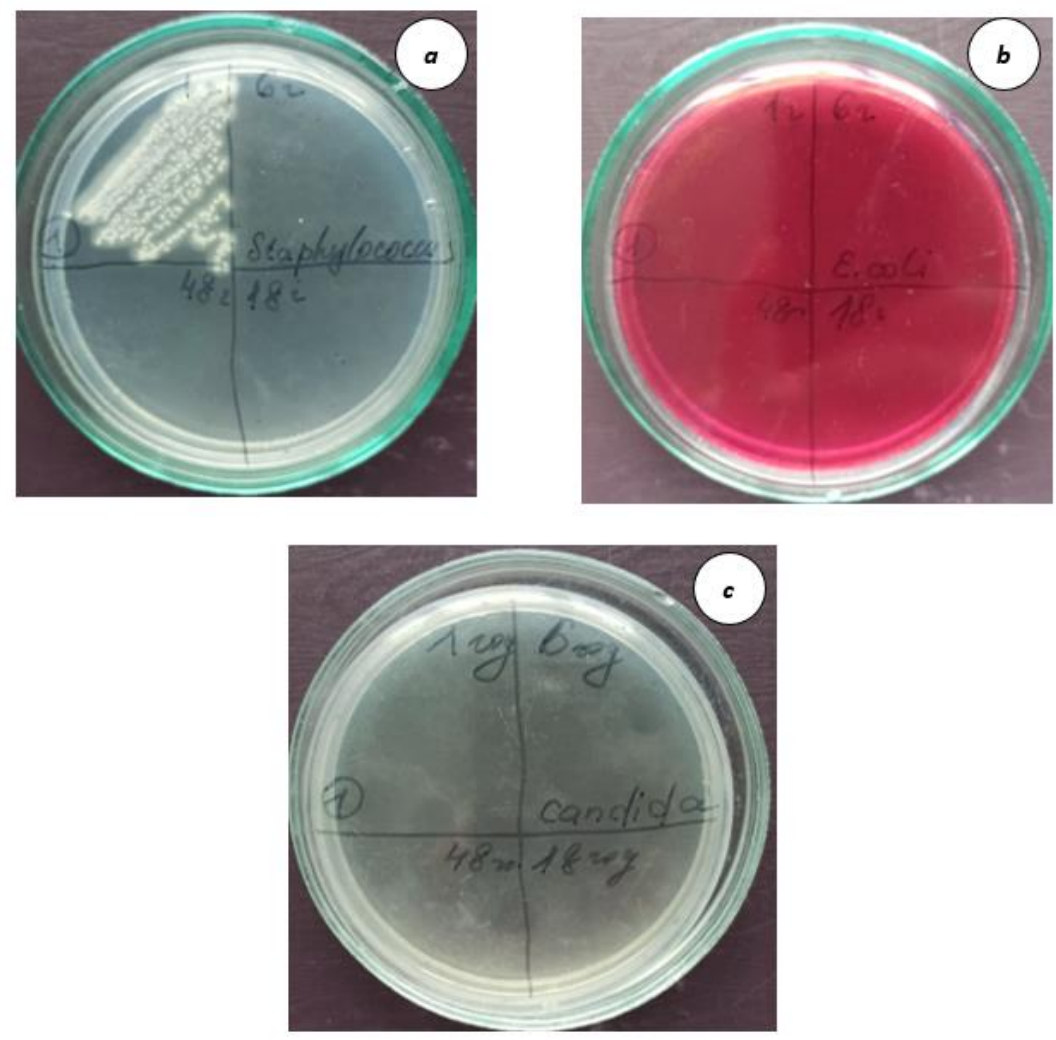

Figure 10. Antimicrobial activity of colloidal solutions of AgNPs synthesized by sonoelectrochemical method at $20{ }^{\circ} \mathrm{C}$ against $S$. aureus ATCC 25923 (a); E. coli ATCC 25922 (b) and Candida albicans ATCC 885-653 (c).

The antimicrobial (disinfection) effect of colloidal solutions of AgNPs synthesized by sonoelectrochemical method at $20{ }^{\circ} \mathrm{C}$ is absolute for strains Escherichia coli ATCC 25922 and Candida albicans ATCC 885-653 (Fig. 10). The antimicrobial activity of AgNPs colloidal solutions synthesized by sonoelectrochemical method at a temperature of $50{ }^{0} \mathrm{C}$ is less pronounced and is absolute only for the Candida albicans ATCC 885-653 (Fig. 11). 

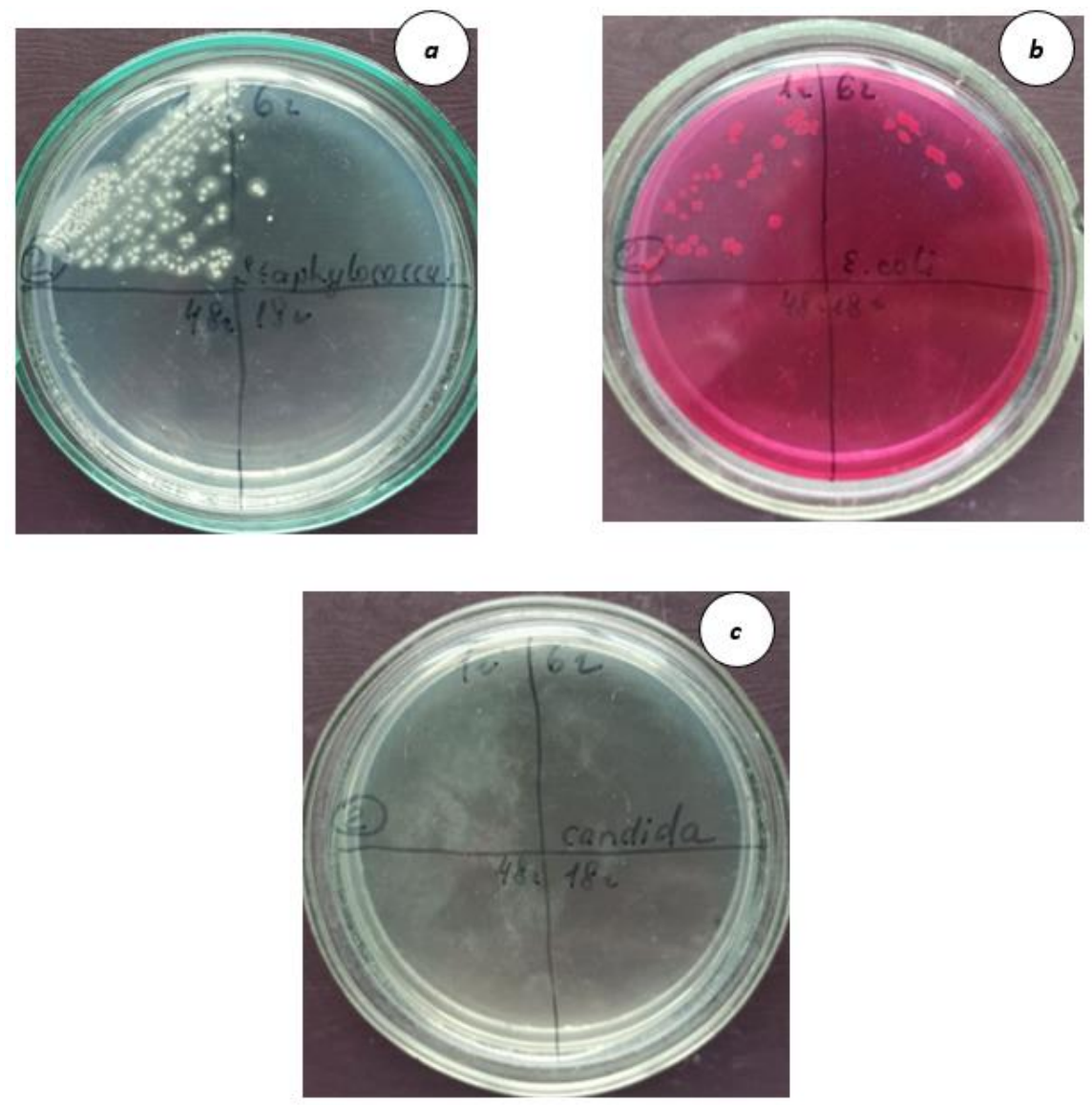

Figure 11. Antimicrobial activity of colloidal solutions of AgNPs synthesized by sonoelectrochemical method at $50{ }^{\circ} \mathrm{C}$ against $S$. aureus ATCC 25923 (a); E. coli ATCC 25922 (b) and Candida albicans ATCC 885-653 (c).

The lower level of inactivation of strains of microorganisms Staphylococcus aureus ATCC 25923 and Escherichia coli ATCC 25922 by colloidal solutions of AgNPs synthesized at $50{ }^{\circ} \mathrm{C}$ may be caused by the higher content of AgNPs with larger sizes (Fig. $7 c^{\prime}$ ), compared to the content of such particles in solutions synthesized at $20{ }^{\circ} \mathrm{C}$ (Fig. $7 a^{\prime}$ ). This means that the increase of the size of AgNPs makes it difficult to fix them on cell membranes by mechanism 1 (vide supra) and, accordingly, leads to a decrease of the antimicrobial activity of the synthesized solutions of AgNPs.

\section{Conclusions}

It was shown that spherical $\operatorname{AgNPs}\left(\lambda_{\max }=500 \mathrm{~nm}\right)$ with sizes up to $30 \mathrm{~nm}$ are formed in NaPA solutions by sonoelectrochemical method using silver sacrificial anodes. The use of silver electrodes under cyclic voltammetry at $\mathrm{E}=1.0 \ldots-1.0 \mathrm{~V}$ in the ultrasonic field allows the synthesis of nanoparticles in a solution of surfactant only. This minimization of the number of precursors contributes to the controllability of the process of formation of AgNPs in size and meets the requirements of "green" synthesis. In addition, the balance of the rates of anodic dissolution of silver and reduction of the formed $\operatorname{Ag}(\mathrm{I})$ ions meets the technological requirements. The rate of AgNPs synthesis increases with increasing of temperature solution and NaPA concentration. As the temperature increases, there is a tendency to increase the size of AgNPs. An increasing increase in the concentration of NaPA leads to a decrease in the size of AgNPs. These parameters are the main in the proposed sonoelectrochemical method of synthesis. The antimicrobial activity of synthesized AgNPs against Staphylococcus aureus, Escherichia coli, and Candida albicans, which are pathogens of nosocomial infections, was 
studied. It was observed that the obtained silver colloids could inhibit the growth of microorganisms.

\section{Funding}

This work was carried out with the partial financial support of the National Research Foundation of Ukraine. Agreement 165/02.2020 (No 0120U105247 "Design of polyfunctional nanostructured mono- and bimetals with electrocatalytic and antimicrobial properties").

\section{Acknowledgments}

This research has no acknowledgment.

\section{Conflicts of Interest}

The authors declare no conflict of interest.

\section{References}

1. Barkat, M.A.; Harshita; B.S.; Naim, M.J.; Pottoo, F.H.; Singh, S.P.; Ahmad, F.J. Current Progress in Synthesis, Characterization and Applications of Silver Nanoparticles: Precepts and Prospects. Recent Patents on Anti-Infective Drug Discovery 2018, 13, 53-69, https://doi.org/10.2174/1574891X12666171006102833.

2. Lee, S.H.; Jun, B.-H. Silver Nanoparticles: Synthesis and Application for Nanomedicine. Int. J. Mol. Sci. 2019, 20, https://doi.org/10.3390/ijms20040865.

3. Talapko, J.; Matijević, T.; Juzbašić, M.; Antolović-Požgain, A.; Škrlec, I. Antibacterial Activity of Silver and Its Application in Dentistry, Cardiology and Dermatology. Microorganisms 2020, 8, https://doi.org/10.3390/microorganisms8091400.

4. Tang, S.; Zheng, J. Antibacterial Activity of Silver Nanoparticles: Structural Effects. Adv. Healthcare Mater. 2018, 7.

5. $\quad$ Grande, R.; Sisto, F.; Puca, V.; Carradori, S.; Ronci, M.; Aceto, A.; Muraro, R.; Mincione, G.; L. Scotti, G. Antimicrobial and Antibiofilm Activities of New Synthesized Silver Ultra-NanoClusters (SUNCs) Against Helicobacter pylori. Front. Microbiol. 2020, 11, https://doi.org/10.3389/fmicb.2020.01705.

6. Cheon, J.Y.; Kim, S.J.; Rhee, Y.H.; Kwon, O.H.; Park, W.H. Shape-dependent antimicrobial activities of silver nanoparticles. Int. J. Nanomedicine 2019, 14, 2773-2780, https://doi.org/10.2147/IJN.S196472.

7. Zhang, Z.; Shen, W.; Xue, J.; Liu, Y.; Liu, Y.; Yan, P.; Liu, J.; Tang, J. Recent advances in synthetic methods and applications of silver nanostructures. Nanoscale Res. Lett. 2018, 13, https://doi.org/10.1186/s11671018-2450-4.

8. Mozaffari, S.; Li, W.; Dixit, M.; Seifert, S.; Lee, B.; Kovarik, L.; Mpourmpakis, G.; Karim, A.M. The Role of Nanoparticle Size and Ligand Coverage in Size. Nanoscale Adv. 2019, 1, 4052-4066, https://doi.org/10.1039/C9NA00348G.

9. Geonmonond, R.S.; Silva, A.G.M.; Camargo, P.H.C. Controlled synthesis of noble metal nanomaterials: motivation, principles, and opportunities in nanocatalysis. An. Acad. Bras. Ciênc. 2018, 90, http://dx.doi.org/10.1590/0001-3765201820170561.

10. Calderón-Jiménez, B.; Johnson, M.E.; Bustos, A.R.M.; Murphy, K.E.; Winchester, M.R.; Baudrit, J.R.V. Silver nanoparticles: technological advances, societal impacts, and metrological challenges. Front Chem. 2017, 5, 1-26, https://doi.org/10.3389/fchem.2017.00006.

11. Mikhailov, O.V.; Mikhailova, E.O. Elemental Silver Nanoparticles: Biosynthesis and BioApplications. Materials 2019, 12, https://doi.org/10.3390/ma12193177.

12. Rajeshkumar, S.; Bharath, L.V. Mechanism of plant-mediated synthesis of silver nanoparticles - A review on biomolecules involved, characterisation and antibacterial activity. Chem.-Biol. Interact. 2017, 273, 219227, http://dx.doi.org/10.1016/j.cbi.2017.06.019.

13. Suvlu, D.; Farshad, M.; Rasaiah, J.C. Nanocluster Growth and Coalescence Modulated by Ligands. J. Phys. Chem. C 2020, 124, 17340-17346, https://doi.org/10.1021/acs.jpcc.0c04459.

14. Compagnini, G.; Condorelli, M.; Fragalà, M.E.; Scardaci, V.; Tinnirello, I.; Puglisi, O.; Neri, F.; Fazio, E. Growth Kinetics and Sensing Features of Colloidal Silver Nanoplates. J. Nanomater. 2019, https://doi.org/10.1155/2019/7084731.

15. Kytsya, A.; Bazylyak, L.; Simon, P.; Zelenina, I.; Antonyshyn, I. Kinetics of Ag300 nanoclusters formation: The catalytically effective nucleus via a steady-state approach. Int. J. Chem. Kinet. 2019, 51, 266-273. 
16. Surudžić, R.; Jovanović, Ž.; Bibić, N.; Nikolić, B.; Mišković-Stanković, V. Electrochemical synthesis of silver nanoparticles in poly(vinyl alcohol) solution. J. Serb. Chem. Soc. 2013, 7, 2087-2098, https://doi.org/10.2298/JSC131017124S.

17. Blandón, L.; Vázquez, M.V.; Benjumea, D.M.; Ciro, G. Electrochemical Synthesis of Silver Nanoparticles and their Potential Use as Antimicrobial Agent: a Case Study on Escherichia Coli. Portugal. Electrochim. Acta 2012, 30, 135-144, https://doi.org/10.4152/pea.201202135.

18. Li, Y.; Qiang, Q.; Zheng, X.; Wang, Z. Controllable electrochemical synthesis of Ag nanoparticles in ionic liquid microemulsions. $\quad$ Electrochem. Commun. $\quad$ 2015, 58, 41-45, https://doi.org/10.1016/j.elecom.2015.05.020.

19. Yanilkin, V.V; Nasretdinova, G.R.; Kokorekin, V.A. Mediated electrochemical synthesis of metal nanoparticles. Russ. Chem. Rev. 2018, 87, 1080-1110, https://doi.org/10.1070/RCR4827.

20. Kuntyi, O.I.; Kytsya, A.R.; Mertsalo, I.P.; Mazur, A.S.; Zozula, G.I.; Bazylyak, L.I.; Topchak, R.V. Electrochemical synthesis of silver nanoparticles by reversible current in solutions of sodium polyacrylate. Colloid Polym. Sci. 2019, 297, 689-695, https://doi.org/10.1007/s00396-019-04488-4.

21. Kuntyi, O.; Mazur, A.; Kytsya, A.; Karpenko, O.; Bazylyak, L.; Mertsalo, I.; Pokynbroda, T.; Prokopalo, A. Electrochemical synthesis of silver nanoparticles in solutions of rhamnolipid. Micro Nano Lett. 2020, 15, 802-807, https://doi.org/10.1049/mnl.2020.0195.

22. Sáez, V.; Mason, T.J. Sonoelectrochemical synthesis of nanoparticles. Molecules 2009, 14, 4284-4299, https://doi.org/10.1007/978-981-287-470-2_11-1.

23. Islam, M.H.; Paul, M.T.; Burheim, O.S.; Pollet, B.G. Recent developments in the sonoelectrochemical $\begin{array}{lllll}\text { synthesis of } & \text { nanomaterials. } & \text { Ultrasonics } & \text { Sonochemistry } & \text { 2019, }\end{array}$ https://doi.org/10.1016/j.ultsonch.2019.104711.

24. Tang, S.; Meng, X.; Lu, H.; Zhu, S. PVP-assisted sonoelectrochemical growth of silver nanostructures with various shapes. Mater. Chem. Phys. 2009, 116, 464-468, https://doi.org/10.1016/j.matchemphys.2009.04.004.

25. Aqil, A.; Serwas, H.; Delplancke, J.L; Jérôme, R.; Jérôme, C.; Canet, L. Preparation of stable suspensions of gold nanoparticles in water by sonoelectrochemistry. Ultrasonics Sonochem. 2008, 15, 1055-1061, https://doi.org/10.1016/j.ultsonch.2008.04.004.

26. Murtaza, M.; Hussain, N.; Ya, H.; Wu, H. High purity copper nanoparticles via sonoelectrochemical approach. Mater. Res. Express 2019, 6, https://doi.org/10.1088/2053-1591/ab48b6.

27. Pollet, B.G. Does power ultrasound affect heterogeneous electron transfer kinetics? Ultrasonics Sonochemistry 2019, 52, 6-12, https://doi.org/10.1016/j.ultsonch.2018.12.017.

28. Ershov, B.G.; Henglein, A. Reduction of $\mathrm{Ag}^{+}$on polyacrylatechains in aqueous solution. J. Phys. Chem. B 1998, 102, 10663-10666, https://doi.org/10.1021/jp981906i.

29. Panáček, A.; Prucek, R.; Hrbáč, J; Nevečná, T.; Šteffková, J.; Zbořil, R.; Kvítek, L. Polyacrylate-assisted size control of silver nanoparticles and their catalytic activity. Chem. Mater. 2014, 26, 1332-1339, https://doi.org/10.1021/cm400635z.

30. Pollet, B.G. The use of ultrasound for the fabrication of fuel cell materials. Int. J. Hydrogen Energy 2010, 35, 11986-12004, https://doi.org/10.1016/j.ijhydene.2010.08.021.

31. Sukhatskiy, Yu.V.; Znak, Z.O.; Zin, O.I. Cavitation and its combinations with other advanced oxidation processes in phenol wastewater treatment: a review. Voprosy khimii i khimicheskoi tekhnologii 2020, 4, 1630, https://doi.org/10.32434/0321-4095-2020-131-4-16-30.

32. He, C.; Liu, L.; Fang, Z.; Li, J.; Guo, J.; Wei, J. Formation and characterization of silver nanoparticles in aqueous solution via ultrasonic irradiation. Ultrason. Sonochem. 2014, 21, 542-548, http://dx.doi.org/10.1016/j.ultsonch.2013.09.003.

33. Ritthidej, G.C. Chapter 3 - Nasal Delivery of Peptides and Proteins with Chitosan and Related Mucoadhesive Polymers. Peptide and Protein Delivery 2011, 47-68, https://doi.org/10.1016/B978-0-12-384935-9.100033.

34. You, F.; Tanga, W.; Yung, L.-Y.L. Real-time monitoring of the Trojan-horse effect of silver nanoparticles by using a genetically encoded fluorescent cell sensor. Nanoscale 2018, 10, 7726-7735, https://doi.org/10.1039/C7NR05975B. 